\title{
Exploiting the Best of Ubuntu and Human Rights for Moral Regeneration: Community Perceptions, Sidhakeni Area, Zhombe District, Zimbabwe
}

\author{
Ndondo Shepherd
}

\begin{abstract}
This study sought to find the perceptions of stakeholders in Sidhakeni area on the use of ubuntu and human rights concepts in fighting sexual abuse, promiscuity and general moral decay. The concepts of ubuntu and human rights were discussed. An interpretive research paradigm was employed because of the nature of data needed to answer the research question. The research found that the concepts of ubuntu and human rights were dysfunctional hence the high rate of moral degeneration in the community. This was attributed to the lack of in depth knowledge about human rights and the concept of ubuntu. Corruption and poverty were also singled out as factors giving rise to the social ills. Gold panning which is rife in the area understudy is also believed to be giving an impetus to this undesirable moral code. This study recommends a rigorous awareness campaign for human rights as they relate to the community's culture. The policing system should be strengthened and a war against corruption should start. Community project for youth should be established with the assistance from individuals, churches, governmental and nongovernmental organizations so as to fight poverty which is perceived to be the bedrock to social ills.
\end{abstract}

Keywords: Sexual abuse, promiscuity, human rights, ubuntu, moral decay

\section{Introduction}

The African moral philosophy of ubuntu and the concept of human rights can be misconstrued as warring factions, yet these two concepts have compatible principles. These two concepts can play complementary roles to help reduce some social ills which include promiscuity, sexual abuse and corruption in Zimbabwean communities. The communitarian nature of ubuntu is well entrenched in the concept of human rights. Just like the philosophy of ubuntu, human rights have accompanying duties and obligations, in both concepts there is need for consideration of one s fellow being. In African traditional societies, an individual was defined in reference to the community. An individual's life can only have meaning in the context of the group, on the other hand, violations of human rights even to one person should be a matter of concern for the entire community. Human rights and ubuntu are not separate entities, in fact, they are a means to the same end. The perception that human rights issues are a Western imposition of foreign culture on Africans is an erroneous one. Human rights concept should be cultured if it is to be imparted in a fruitful sense, it should be done in a cultural context. There must be a strong synchronization of human rights and cultural norms and values. The fact that people have different norms and values justifies the variation in the ways different cultural groups define human rights. Confronted with social ills like promiscuity, sexual abuse and corruption in the area under study, this research sought to examine the employment of ubuntu and human rights in reducing sexual abuse, promiscuity, corruption and general moral decay in Sidhakeni area. As these two concepts overlap, the emphasis is in getting the best from these concepts to fight these social ills.

\section{Background of the Study}

Sidhakeni area is located in Zhombe district in the Midlands province of Zimbabwe. The economic activities in the area are believed to be the wellspring of social ills bedeviling a rather well resourced community. The area is naturally endowed with gold deposits. Because of this, the main economic activity for the locals is gold panning. This has also attracted fortune seekers from all corners of the country. While gold panning is the main source of livelihood for the community, it has brought with it some harm in the community's moral make up. One alarming feature which is noticeable in local schools is the high rate of school dropouts. In trying to find out the causes of this high rate of school dropouts, in many cases early marriages, pregnancies and issues related to sexual abuse are singled out as the principal causes. A snap survey shows that these cases are being fuelled by gold panning, the main economic activity in the area. A rush for a quick buck has led youngsters to drop out of school at an early age. Upon getting their money after hard work, gold panners are well known for their extravagant way of spending money. They splash money on beer, intoxicating drugs and womanising. Indulgences in unsafe sex often lead to unwanted pregnancies and disease. The most vulnerable of these sexual offences are school children who because of poverty are lured by gold panners into these social vices. It is against this backdrop that this research sought find from stakeholders how the concepts of ubuntu and human rights could be used to fight these social ills. It is therefore imperative at this point to briefly visit the two core concepts in this study.

\section{Purpose of the Study}

This study sought to find the perceptions of stakeholders in Sidhakeni area on the use of ubuntu and human rights concepts in fighting sexual abuse, promiscuity and general moral decay.

\section{Ubuntu Philosophy}

Ubuntu is the root of African philosophy. Ubuntu is the well spring flowing with African ontology and epistemology (Ramose, 1999). Ubuntu is the basis of 


\section{International Journal of Science and Research (IJSR) \\ ISSN (Online): 2319-7064}

Index Copernicus Value (2013): 6.14 | Impact Factor (2014): 5.611

African philosophy which is mainly premised on humane principles. A human being is to affirm one $\mathrm{s}$ humanity by recognizing the humanity of others and on that basis establish humane relations with them. Ubuntu understood as being human (humanness); a humane, respectful and polite attitude towards others constitute the core meaning of this euphorism-umuntu ngumuntu ngabantu (A person is a person because of other human beings). The crisis the continent is facing today may need a glare of an African solution. It calls for a "back to basics" attitude. Although it is well understood that African culture cannot be captured in its original genre, it can be argued that some basic principles can be revisited to address some of the problems Africa is facing today (Makuvaza, 1996). Nicholson (2008), echoed the view that African crisis need an embrace of traditional African ethics. He argues that the enhancement of traditional African ethics would curb the crises in Africa namely moral crises of corruption, diseases, self-enrichment and the growing list of their effects, conflict mismanagement, poverty and other disastrous outcomes. Education can be understood as the induction into culture (Lawton, 1975). African traditional education bore its strength in maintaining essential African values for the society by closely identifying children with the life of the group, the community, family, totem, the village or any other term of social organization (Peresu and Nhundu, 1999). The interdependence of the group was much cherished and individualism was shunned. The system went out of its way to introduce in the individual a decent code of behavior which had consideration for one's fellow man (Makuvaza, 1996; Samkange and Samkange, 1980). The education system sought to educate the children how to live in friendly terms with those around him, according man the respect a human being deserves (Gelfand, 1979). It was geared to creating politeness, correctness, mutual respect and dignity (Laye, 1965). With all these humane qualifications instilled in the young, it was uncommon to hear of social vices which are now a common place in African societies today. Puberty, a transitional stage from childhood to adulthood is a critical stage in human development. Incognizance of this, the African traditional education system at this stage focused on acculturating in boys and girls models of ideal men and women. Peresuh and Nhundu (1999) argue that an ideal man preserved and strengthened cultural, social and moral features of the society and the ideal woman was a wife and mother who through the bearing of children and in her role as educator assisted her husband in the task of preserving and strengthening the customs and traditions of the group. The quality of sex education that adolescence received was such that purity was kept until marriage (Gelfand, 1979).It is the submission of this paper that if the basics of this philosophy be embraced to curb social vices bedeviling the community. This needs concerted effort from the government, nongovernmental organizations and the whole community in general as Nziramasanga(1999) hinted that ubuntu should know no boundaries and should be engaged everywhere, anytime by anyone.

\section{Human Rights}

Human rights imply a universal ethic which claims that certain rights are to be believed and observed everywhere and by everyone (Soni, 2002). The concept of human rights came as a need by the human race to lead a dignified life after the Second World War. It can be argued that human rights are as old as humanity as reflected in the worldes religions. The concept is also very evident in African traditional societies. This is an endeavor by mankind for a life in which inherent dignity and worth of human being will recover respect and protection. Due to many varied societies with different sets of values, the concept of human rights ceases to have one clear definition. This is because human rights should be understood in the context of different cultural set-ups. This is also echoed by Sen (2011) when he says human rights teaching must be conditioned by the values and ethics of the society. Nziramasanga(1999) puts it clearly when he says human rights existed before hence the importance to research into what already existed in culture and subsequently build on that. In support of this assertion, Mabovula (2011) echoed that ubuntu should be regarded as one of the origins of the development of human rights. The philosophy espouses a fundamental respect in the right of others as well as a deep allegiance to the collective identity. Ubuntu regulates individuality and emphasizes sharing and co-responsibility (Mabovula, 2011). The outstanding impact of ubuntu is the value it puts on human dignity. It is mainly humanism that finds expression in a communal context rather than individualism (Teffo, 1998). This therefore dispels the widespread erroneous impression that human rights are a Western concept which is being imposed on Africans by the Western powers. The concept of human rights is not selfish, it brings with it responsibilities. In most cases, human rights awareness had not emphasized the aspect of responsibility and therefore it seemed to erode morals (Nziramasanga, 1999). There is a need to strike a balance between rights and responsibilities so as to curtail excessive freedom which in most cases leads to the violation of other people e rights. The emphasis on responsibility is likely to have a strong bearing on attitude and behavior change in matters of sexuality. The emphasis is, in whatever one does, a consideration of one $\mathrm{s}$ fellow human being is imperative. The first step towards the realization of the effectiveness of human rights is the awareness of the human rights concept. Sen(2011)puts it aptly when he says, "for proper implementation of human rights it is necessary for everyone to know his or her own rights as there is a close relationship between legislation, implementation and education". The same idea is also emphasized in Article 26 (2) of the universal declaration of human rights which says that education shall be directed for the full development of the human personality and the strengthening of respect for human rights and fundamental freedom. This is very crucial as it therefore calls for one to be aware of his/her own rights to ensure that they are not violated. If one wants to protect his/her rights from being trampled on, it logically implies that one will have a respect for the rights of others. The delivery of human rights education should be in line with the cultural values of a particular society. Notwithstanding the need for teaching of human rights in the formal school curriculum it is also important to note that a reflection of this concept in the hidden curriculum is imperative. This can be done through the creation of a school atmosphere that promotes the respect of human 


\section{International Journal of Science and Research (IJSR) \\ ISSN (Online): 2319-7064}

Index Copernicus Value (2013): 6.14 | Impact Factor (2014): 5.611

rights. This can be fostered by providing a democratic environment enabling children to enjoy their rights and simultaneously learn to respect the rights of others (Babarinde, 1994).

In order to realize the effectiveness of human rights, adult education programmes should be put in full force. Teaching of human rights must have a practical orientation (Soni, 2007). Adult education programmes should equip them with the ability to defend human rights and fight against abuse of authority. It should instill that assertiveness in adults that their rights will not be trampled on. Sen (2011) argues that human rights violations are frequent and rampant because people are not active and vigilant. In a bid to observe human rights, it should be understood that poverty is one of the most potent causes of human rights isolation especially in developing countries. Poverty undermines human dignity and without dignity there are no human rights (ACPD 2006).

\section{Methodology}

This study took an interpretive research paradigm as it sought to find perceptions of stakeholders on the use of ubuntu and human rights to fight promiscuity and sexual abuse. A case study design was employed to get perceptions from a three strata population in Sidhakeni area in Zhombe district. This included community leaders, teachers, and community members. A purposive sampling technique was used to come up with a sample of fifteen (15) teachers from three schools, ten (10) community leaders which comprised school heads, village heads, headmen, chief senior police officers and pastors and ten (10) community members. Questionnaires were administered to all participants. Five community members and five (5) teachers were randomly chosen for interviews. All community leaders were interviewed. The questionnaire gathered participants ${ }^{e e}$ bio data such as gender, age and whether participants had some knowledge of the concepts of ubuntu and human rights and also the state of sexual abuse, promisuity and other moral vices. The purpose of including community leaders in the sample was to have their views on human rights, traditional norms and values as these are the custodians of African culture. Teachers were also included so as to find out how conversant they are on the two concepts and how the social ills can be reduced through the curriculum. Community members were there to express the extent of the problem and give their views on how the concepts can be used to address the problems bedeviling the area under study.

\section{Findings}

\section{Understanding of Human rights}

The general feelings among community members were that human rights are the fundamental entitlements to all human beings. Basic freedoms which enable people to live in the community without much inference were noted as one of the best qualities of human rights. It was indicated that human rights were fostered in the curriculum through some subjects like Social studies and Religious and Moral
Education at primary school level. Some teachers however lacked a proper orientation on human rights such that they felt teaching of human rights would give pupils excessive freedom leading to indiscipline.

Community leaders however reported that although they feel that human rights foster democracy and make people live well with others some viewed the concept otherwise. They felt that human rights are a problematic concept in that people are no longer conforming to the required standards of behavior. Young people no longer respect traditional norms and values and also traditional leaders who are custodians of these values.

In the same vain some community members felt that the issue of human rights has led women to undermine the authority of men. It is generally believed that corruption that has gripped the community has rendered the human rights concept useless. This reveals a gross misconception of human rights, the concept of human rights is perceived without obligations and also it is being understood out of cultural context. Soni(2007)argues for the importance of teaching human rights in terms of a web of inter individual and societal duties. Teaching of human rights should strongly emphasize duties and responsibilities. It should be noted that freedom is an elusive concept and there is no absolute freedom. Nicholson (2008) notes that though the issue of human rights is greatly valued globally, humanity is still caught in a whirlpool of problems leading to blatant violation of human rights. This, in most cases is the failure by citizens to take responsibility of their actions leading to very big gap between theory and practice.

\section{Understanding of Ubuntu and its effectiveness}

Ubuntu was well understood as cultural behavioral term. The choice of sexual partners is defined by the standards of the community. The high moral decadence in the community was pointed out as evidence to how ubuntu has become dysfunctional. A community member echoed that

"Ubuntu has produced desirable products in the past, but now the concept is hardly functional in this community".

This is in line with Nziramasanga(1999) who reported a high state of moral decadence that seemed to have set in and was running through all the strata of society. This was attributed to a weakened sense of culture and religion which had left many people uprooted and adrift. Teachers revealed that the concept of ubuntu was reflected in the curriculum through subjects like Social studies, Religious and Moral Education, Shona and English. There was a strong feeling among teachers that sports and school regulations that foster acceptable behavior and subjects that remind children about their responsibilities and duties were the curriculumes bid to instill ubuntu.

\section{Causes of Sexual Abuse and Promiscuity}

Having admitted that there is a high rate of moral decay in the form of sexual abuse and promiscuity; participants attributed these social ills to different reasons. Poverty is believed to be one of the root causes of moral decay. Due 


\section{International Journal of Science and Research (IJSR) \\ ISSN (Online): 2319-7064}

Index Copernicus Value (2013): 6.14 | Impact Factor (2014): 5.611

to the recurrent drought, some people become so poor that they can hardly sustain their lives. It became clear that most people get their livelihoods through illegal gold panning which they popularly refer to as "Korokoza". By its nature, gold panning is labour intensive. Most participants indicated that gold panners have a tendency splashing much of their income in beer drinking and prostitution as a way of relaxing.

Because of this quick cash syndrome from gold panning, it emerged that pupils are dropping out of school at a tender age. After dropping out of school, and in possession of money from gold panning, these youngsters, it was pointed, develop some, freedoms ${ }^{e e}$ which lead them to indulge in beer drinking, drugs and illicit sexual activities. Participants felt that the most vulnerable group is that of girls from the poor socio economic background. These children are susceptible to sexual abuse as they are easily attracted to splashy life from gold panners with a hope of being redeemed from poverty. This has caused indiscipline, sexual abuse and promiscuity with the youth in schools not spared of these vices.. Most participants expressed hopelessness in reporting cases on sexual abuse. The feeling among participants was that poverty and corruption were the major forces fuelling sexual abuse. Parents or guardians of abused children are bribed not to report cases of sexual abuse. On the other hand participants indicated that law enforcement agents are also bribed and these cases are swept under the carpet such that reporting cases of sexual abuses has proved to be a futile exercise.

It was also reported that the need for money has led to many cases of infidelity as married women give sexual favours to gold panners for monitory gains. A participant remarked: "Gold panning is the main cause of sexual abuse and promiscuity, as men find themselves with cash, women flock towards them for subsistence through sexual favours."

It was noted that the misconception of human rights concept is fuelling promiscuity as people feel that they have the right to indulge into multiple sexual relationships. Some participants felt that some youngsters are led into these moral vices mainly because of group influence. They, in most cases realize the harm when the damage is already done. Participants felt that sexual abuse in on the increase because perpetrators are not punished and the abused lack protection from law enforcers.

\section{Human Rights, Sexual Abuse and Promiscuity}

Participants generally felt that human rights education has a lot of flaws leading to the dysfunction of the human rights concept. Some participants felt that a lot need to be done in the human rights delivery system .Parents felt that children develop a lot of freedoms which in turn fuel sexual licentiousness mainly because "Some human rights educators talk about sexuality to a group of parents and children without separating them, so children feel that they have the same status as their parents".
Whilst it was appreciated that there are some known pieces of legislation that protect both adults and children from sexual abuse, much has not been done towards the enforcements of the legislations. As human rights are protected by the law, it was hoped that as legal entitlements, perpetrators were supposed to be punished. On the contrary, it was reported that perpetrators of sexual abuse normally get away with it through bribery. A Community leader remarked that "There is no sense to talk about human rights in a community riddled with corruption, like oil and water the human rights and corruption will not mix". Many cases of sexual abuse go unreported because the abused or their parents do not know the correct procedures to report these cases or they feel that they are not protected by the people who are supposed to be the custodians of the law (Ndondo, 2014)

\section{The Understanding of Ubuntu and Its Function in the Community}

Most of the participants generally agreed that ubuntu is dysfunctional. A high rate of moral decay in form of corruption, sexual licentiousness, general disrespect of onees fellow human beings and traditional institutions. This type of behavior was mainly attributed to poverty, high rate of corruption in the society and the need for self enrichment. The general feeling was that some youngsters have lost conscience, promiscuous behavior is a common place, and sexual abuse is going on unchecked. It was noted that children born out of these shaky unions lack role models inform of parents and they are likely to live the same miserable lives experienced by their parents. In line with this Nziramasanga(1999) who underscores that one of the major causes of moral decadence was the dearth of role models in teachers, leaders, family and society. It was also reported that the same traditional leaders who are expected to be custodians of traditional values tend to be perpetrators of sexual abuse.

\section{Measures to Make Human Rights and Ubuntu Effective}

Respondents felt that human rights and ubuntu can be made functional through approaching these concepts within a broad spectrum. Human rights awareness campaigns were to be intensified with emphasis on duties and responsibilities. According to Nziramasanga (1999) human rights awareness had not emphasized the aspect of human responsibilities and therefore it seemed to erode morals. Human rights education could be done through workshops involving all stakeholders in the community. Participants felt that human rights education should be strongly aligned to the culture of a people so as to make reconciliation with ubuntu. Soni (2007) concurred with this view when he says, "For human rights education to be effective it must be patterned on the culture and genius of the society". Participants believed in the exploitation of the similarities between the two concepts to get the most desired behavior patterns. A call to blend the two concepts with Christian values was made. Since Christianity preaches the gospel of love and respect for one being, the community members should be made to realize that the principles of human rights and ubuntu are to a 


\section{International Journal of Science and Research (IJSR) \\ ISSN (Online): 2319-7064}

Index Copernicus Value (2013): 6.14 | Impact Factor (2014): 5.611

large extent compatible with Christian values. It was noted that the task of this nature hardly works without a strong policing system hence some enforcement measures should be put in place. This should start from the family, the school up to community leaders. The work of law enforcement officers, teachers and community leaders was highly valued in making ubuntu and human rights more effective. Teachers and parents would create the good environment to foster human rights and ubuntu, whilst the police officers and community leaders would enforce the ideals. It was also observed that poverty was the root cause of moral decay in the community, because of this, a sustainable way of fighting sexual abuse and promiscuity were generally viewed as more desirable. There was a call for the creation of income generating projects for the youth and old for poverty alleviation. Fighting of poverty and corruption was viewed as imperative as morality is likely to take a positive turn if people are economically empowered in a corrupt free environment.

\section{Discussion}

The findings from this study revealed that although people have a basic understanding of human rights, they seem not to understand the duties and responsibilities associated with human rights. The majority of the respondents take the freedom associated with human rights slavishly. They fail to take into cognizance that no freedom is absolute. In reference to the right to freedom, the existentialist philosopher, Satre says everybody is forced to do what he/she wants but remember that to be totally free, you have to realize the freedom of others. Sexual abuse is a gross disrespect of one ss fellow being, an undermining of one $\mathrm{s}$ dignity. The perpetrators exercise ,jungle freedom "e which was not ever cherished by humanity. The act of sexual abuse leaves an indelegible mark in the mind of the abused, relatives and the society at large. On the other hand promiscuity as a social ill cannot go without impacting negatively on community members even those who are not involved in it.

This irresponsible behavior is the root cause to single parent families, disease, child headed families and orphanage. This will trigger a multiplicity of human rights violations. As family life is generally impoverished because of these vices, children will be deprived of the right to the basics of life like education, shelter, clothing and food. There is no freedom without obligations, people should be responsible for their own actions, and their freedom should not affect the freedom of others. This finds support from old time philosophers like Immanuel Kant who through his moral laws hinted that whatever one does should be a universal law, meaning that it should apply to everybody including the doer. Most of the world's major religions support this freedom with Christianity saying „,Do unto others as you would like them do unto you eee. It is imperative to note that human rights should also be taught in a cultural context, thus some cherished cultural norms and values should be aligned to the teaching of human rights. To this effect Sen (2011) argues that human rights teaching on the other hand must be conditioned by the values and ethos of the society. This dispels the misguided feeling by community members that the concept of human rights comes as a relief to an authoritarian traditional environment.

Notwithstanding the weaknesses in todayes traditional institutions, these are the custodians of African traditional values, so they need respect and support from the community. This misguided thinking and failure to align human rights to cultural norms and values led to the perception that human rights have caused moral decay (promiscuity). The school is an indispensible institution in the socialization of the young justified by the fact that children spend most of their time in schools from a very tender age. It is therefore critical that teachers have an in depth knowledge about human rights as they relate to our culture. Human rights should get a place in teacher education curriculum. Teachers ${ }^{\text {ee }}$ endeavour to create a democratic environment in which children are free to express themselves taking responsibility of what they say and do.

Ubuntu is generally dysfunctional mainly because of corruption which has filtered into traditional institutions and law enforcement agencies. The state of moral decay leading to high rate of sexual abuse and promiscuity is also attributed to the talk about human rights. The majority of community member lack in-depth understanding of the concept. It should be understood that the concept of ubuntu and human rights are not conflicting but rather complementary. The overlaps between the concepts should be strongly exploited to produce the best possible products in the community. When talking about ubuntu, people are tempted to think that they are being dragged back to the traditional past. Most people understand this as the challenge of applying an ancient or pre modern wisdom in post modern society (Nicholson 2008). This is rather not possible, the power of change is strong; culture cannot be spared of this dynamism. There are elements of foreign culture which inevitably come into our culture because of us being a member of the global community. It is therefore imperative for us to consider those elements which are compatible with our cultural norms and values and make a hybrid culture with our culture being a guiding principle. The economic activity in the area, poverty and lack of indepth knowledge on human rights and ubuntu precipitate social ills in Sidhakeni area. Because of these findings, this paper therefore calls the blending of human rights and ubuntu so as to have an intervention on sexual abuse and promiscuity.

As most of the populace is Christian and Christian values are compatible with the values for ubuntu and human rights, an opportunity presents itself to exploit this platform in educating community members that adhering to our Africa traditional values is not going back to ancient times, rather some different, ,contemporary ${ }^{e e}$ cultural grouping are adhering to the same norms. Above all, an effective enforcement system is needed for ubuntu and human rights to be functional. The family must play its role, the school should complement the family effort, and traditional leaders should be respected and should execute their duties delligently. Thing can be done through continual education on human rights and ubuntu by 


\section{International Journal of Science and Research (IJSR) \\ ISSN (Online): 2319-7064}

Index Copernicus Value (2013): 6.14 | Impact Factor (2014): 5.611

traditional leaders, governmental organization, nongovernmental organizations and churches.

\section{Conclusion}

From the findings of this study it can be concluded that poverty and lack of in depth knowledge on the concept of human rights and ubuntu is the root cause of social ills in Sidhakeni area. This has been fuelled by gold panning which is the main economic activity in the area. Most young people have nothing decent for their livelihood in the area, young men flood the gold panning sites. When they get money from the activity after a hard work, they have a tendency of enticing young women who mainly because of poverty and the need for quick cash, easily fall into a multiplicity of sexual relations. The effort by victims or relatives of sexually abused to pursue justice through the legal system are frustrated by corrupt and decaying legal structures. As long as a corrupt system is not checked, sexual abuse will remain a common phenomenon. Corruption which has become cancerous in the society has rendered efforts to halt this moral degeneration useless. It can be concluded that there is a great need for a vigorous cultural and human rights education. Human rights education should be done in a cultural context for people to appreciate their culture at the same time tapping the good elements from foreign cultures. This study calls for a broad based approach in campaigning for human rights and ubuntu if sexual abuse and promiscuity are to be halted in the community. Despite having a lot of workshops on human rights in the community, the quality of presentation must be improved through emphasizing duties and responsibilities. When people know their rights they will be in a better position to claim them if they are trampled on. Would-be perpetrators of human rights violations are likely to exercise a form of restraint in their behaviour. It also implies that traditional leaders should be compelled to continually emphasize the acceptable moral contacts in the community as they are the custodians of ubuntu. The community leaders should join hands and be innovative in the creation of community projects for the youth to have more descent livelihoods. An effective enforcement system must be put in place for the exercise to bear fruits. This however is not any easy task as it needs a concerted effort from all stakeholders.

\section{References}

[1] African Community publishing and Development Trust (2006) The Rainbow encircling the people: An African guide to democracy. CapeTown: ACPDT

[2] Babarinde, K. (1994) Can schools Teach Democracy. Zimbabwe Journal of Educational Research, 6(2), 225-239

[3] Soni, S. K (ed) (2007) Human Rights Concepts. Issues. Emerging Problem. New Delhi: Regal publications

[4] Sen, A .S (2011) Human Rights in a developing society. New Delhi: APH Publishing Corporation

[5] Nziramasanga, C.K (1999) Report on the presidential commission of inquiry into education and training. Harare: Government printers
[6] Maura, W. P and Sakala E (eds)(1999) Yes, You Do count. A comprehensive training programme on human rights. Harare: CCJP

[7] Starkey, H (ed)(1991)The challenge of Human Rights Education. London: Cassel Educational Ltd.

[8] Ndondo, S (2014) Human rights: Perceptions and making the discourse functional: A case of Gokwe central community. International Journal of Scientific and Research Publications 4 (4)

[9] Ramose, M. B(1999) African philosophy through ubuntu. Harare: Mond Books

[10] Samkange, S and Samkange TM (1980) Hunhuism or Ubuntuism: A Zimbabwean indigenous political philosophy. Harare: Graham Publishing 